\title{
Intelligent Product Quality Failure Prediction System in Smart Factories Based on Machine Learning Techniques
}

\author{
Tainá da ROCHA ${ }^{1}$, Anderson Luis SZEJKA and Osiris CANCIGLIERI JUNIOR \\ Industrial and Systems Engineering Graduate Program (PPGEPS), Pontifical Catholic \\ University of Parana (PUCPR), Curitiba, Brazil
}

\begin{abstract}
Industry 4.0 has brought innovative principles to the entire world, especially for the manufacturing industry. The adaptation to a technological era showed limitations in the current processes, of which we can highlight the divergence between software and machinery technologies, cloud data processing, difficulty for the information to circulate within a manufacturing environment, so that it flows clearly and objectively, without ambiguity. These limitations end up generating errors between operations in the manufacturing process resulting in costs, customer dissatisfaction, low product quality, and reduced competitiveness. Thus, problems related to the semantic web, semantic interoperability, horizontal and vertical integration are responsible for such limitations in manufacturing processes. To resolve such restrictions and improve the final quality of the product, it is possible to apply Machine Learning techniques. Through the use of ensemble models of machine learning algorithm techniques, techniques with specific characteristics can be grouped, complementing each other, thus providing better prediction results during the manufacture of products, reducing costs, increasing the reliability and quality of the final product. In this way, it is expected to improve the final quality of the product and minimize the impacts that detract from the performance indicators, such as scrap, cost, rework, labor. This research will contribute scientifically to the creation of a system, which can be applied in different manufacturing production processes.
\end{abstract}

Keywords. Manufacturing Systems, Semantic Interoperability, Product Quality, Horizontal and Vertical Integration, Machine Learning, Artificial Intelligence.

\section{Introduction}

In recent years, the strong competitiveness of the market has brought about the need to change by new ways of making products, faster, less costly, and with better quality. Thus, one of the impacting and indicative factors are the quality and performance indicators, of which they are directly linked to the organization's business strategy [1].

According to the demand coming from Industry 4.0, it is noted that many points were diverging, such as the need for all information that circulates within a manufacturing environment to flow clearly and objectively, so that there is no possibility for distortion, ambiguity, loss of information during communication, errors between operations in the manufacturing process resulting in costs, customer dissatisfaction, low product quality and low competitiveness [2][3].

The transdisciplinary between dealing with product quality issues, manufacturing performance indicators, using machine learning techniques from industry 4.0 are

\footnotetext{
${ }^{1}$ Corresponding author, Mail: rocha.taina@hotmail.com.
} 
intercepted, complementing each other and collaborating to achieve the same result: continuous improvement of the process/product and customer satisfaction.

Heterogeneity occurs in environments composed of different sectors (suppliers, purchases, logistics, projects) that interact with each other, which can be via system or physical, with a common goal: optimize manufacturing processes by integrating it vertically and horizontally, increasing quality and make new products viable, thus remaining competitive to the market. It is in this line of strategy that companies are strengthening their horizons, making their factories intelligent, autonomous, flexible, iterative, independent, with fast data processing and easy access, and with reliability, to make decision making much faster and decentralized [1].

To achieve this goal, companies have invested heavily in networks of increasingly robust systems, such as the Semantic Web, so that the exchange of information happens more efficiently and productively, this process is called Interoperability. Interoperability can be classified according to [4][5][6], as the ability of a system or set to communicate transparently / clearly with others, thus working with open standards, ontologies, or Machine Learning techniques.

Thus, through the use of machine learning techniques, it will act for better interoperability between machines and integration of processes, products. Through the use of ensemble models (set) of machine learning algorithm techniques, techniques with specific characteristics can be grouped, complementing each other, thus providing better prediction results, reducing costs, increasing reliability and product quality and services. This type of ensemble model has been used more and more, due to the positive results presented by the application, bringing improvements.

\section{Problem Statement}

The use of Industry 4.0 for industrial processes allows for higher product quality. After all, the greater the control over a given operation, the better the efficiency of the production chain and, consequently, of the merchandise that reaches the customer [2].

It can be seen that the flow of information between the manufacturing is complex, agile, and with no room for errors. The ability of independent companies and heterogeneous information systems to semantically interoperate is related to the challenges of making their semantics explicit and formal so that messages are not only ex-changed but interpreted, without ambiguity [8]. Within an organization, the main concern is to meet the customer's expectations and requirements with a product/service, respecting specifications, quality and costs.

In this way, this work aims to demonstrate the transdisciplinarity of the themes involved in several articles related to the theme, to demonstrate their contribution and how complementary they are. The objective was to select articles aimed at the manufacturing industry and product quality, and which had examples of applications in problems involving themes related to semantic interoperability, horizontal and vertical integration, application of Machine Learning techniques. 


\section{Literature Review and Classification}

A literature review was conducting in the Periódicos Capes Database, which it has more than 532 scientific databases, such as SCOPUS, IEEE Xplore, Taylor and Francis, Emeralds, and so on. This literature review search papers with keywords relate to: Quality (focusing on the product), Manufacturing and Horizontal Integration and/or Vertical (focusing on information, communication within the manufacture). The results of this findings were classified following the structure presented below and the Table 1 presents the results of this classification.

- $\quad$ T1 - Product Quality: Articles focused on Product Quality.

- T2 - Product and Process Quality: Articles that deal with process problems as it impacts product quality, acting on this synergy, however, the main focus is product quality.

- $\quad$ R1 - Industrial Manufacturing: Articles focused on manufacturing processes.

- R2 - Manufacturing (scope): Articles that are also adding other areas such as logistics, hospital, and are not exclusive in manufacturing processes.

- N1 - Horizontal and/or Vertical Integration: Articles that address the exchange of information and knowledge between manufacturing processes, more specifically between machines (operations).

- $\quad \mathrm{N} 2$ - Horizontal and/or Vertical Integration (comprehensive) - Articles that deal with issues related to the exchange of information and knowledge, but in a comprehensive and managerial way (MES system, management, sustainability).

Table 1. Classification of articles by keywords

\begin{tabular}{|c|c|c|c|c|c|c|c|}
\hline Name Article & T1 & $\mathbf{T 2}$ & R1 & $\mathbf{R 2}$ & N1 & $\mathbf{N 2}$ & $\begin{array}{c}\text { Accepted } \\
\text { Article }\end{array}$ \\
\hline $\begin{array}{l}\text { Organizational and managerial challenges in the path } \\
\text { toward Industry } 4.0\end{array}$ & & & & $\mathrm{X}$ & & $\mathrm{X}$ & No \\
\hline $\begin{array}{l}\text { Development of an open source-based manufacturing } \\
\text { execution system (MES): industry } 4.0 \text { enabling } \\
\text { technology for small and medium-sized enterprises }\end{array}$ & & & & $\mathrm{X}$ & & $\mathrm{X}$ & No \\
\hline $\begin{array}{l}\text { Digital transformation of manufacturing through cloud } \\
\text { services and resource virtualization }\end{array}$ & & & & $\mathrm{X}$ & & $\mathrm{X}$ & No \\
\hline Centrolac & & $\mathrm{X}$ & & & & $\mathrm{X}$ & No \\
\hline $\begin{array}{l}\text { Assessing Industry } 4.0 \text { readiness in manufacturing: } \\
\text { Evidence for the European Union }\end{array}$ & & & & & & $\mathrm{X}$ & No \\
\hline $\begin{array}{l}\text { The impacts of different } \mathrm{ReD} \text { organizational structures on } \\
\text { performance of firms: Perspective of absorptive capacity }\end{array}$ & & & & & & $\mathrm{X}$ & No \\
\hline $\begin{array}{l}\text { Design and management of manufacturing systems for } \\
\text { production quality }\end{array}$ & $\mathrm{X}$ & $\mathrm{X}$ & $\mathrm{X}$ & & $\mathrm{X}$ & & Yes \\
\hline $\begin{array}{l}\text { The expected contribution of Industry } 4.0 \text { technologies } \\
\text { for industrial performance }\end{array}$ & & & $\mathrm{X}$ & & & $\mathrm{X}$ & No \\
\hline $\begin{array}{l}\text { Impact of quality of service on cloud-based industrial IoT } \\
\text { applications with OPC UA }\end{array}$ & & $\mathrm{X}$ & $\mathrm{X}$ & & $\mathrm{X}$ & & Yes \\
\hline Dynamics of resource sharing in production networks & & & & $\mathrm{X}$ & & $\mathrm{X}$ & No \\
\hline $\begin{array}{l}\text { The future of manufacturing industry: a strategic } \\
\text { roadmap toward Industry } 4.0\end{array}$ & & & & $\mathrm{X}$ & & $X$ & No \\
\hline $\begin{array}{l}\text { Firm Boundaries, Information Processing Capacity, and } \\
\text { Performance in Manufacturing Firms }\end{array}$ & & & & & & $X$ & No \\
\hline
\end{tabular}




\begin{tabular}{|c|c|c|c|c|c|c|c|}
\hline Name Article & T1 & $\mathbf{T 2}$ & $\mathbf{R} 1$ & $\mathbf{R 2}$ & N1 & $\mathbf{N 2}$ & $\begin{array}{c}\text { Accepted } \\
\text { Article }\end{array}$ \\
\hline $\begin{array}{l}\text { Building a new culture for quality management in the era } \\
\text { of the Fourth Industrial Revolution }\end{array}$ & $\mathrm{X}$ & & & & & & No \\
\hline $\begin{array}{l}\text { Sustainable Industry } 4.0 \text { framework: A systematic } \\
\text { literature review identifying the current trends and future } \\
\text { perspectives }\end{array}$ & & & & & & $\mathrm{X}$ & No \\
\hline Literature review of Industry 4.0 and related technologies & & & & & & $\mathrm{X}$ & No \\
\hline
\end{tabular}

\begin{tabular}{|c|c|c|c|c|c|c|c|}
\hline $\begin{array}{l}\text { Assessing the value of information of data-centric } \\
\text { activities in the chemical processing industry } 4.0\end{array}$ & & & $\mathrm{X}$ & $\mathrm{X}$ & & $\mathrm{X}$ & No \\
\hline $\begin{array}{l}\text { A training system for Industry } 4.0 \text { operators in complex } \\
\text { assemblies based on virtual reality and process mining }\end{array}$ & $\mathrm{X}$ & $\mathrm{X}$ & $\mathrm{X}$ & & $\mathrm{X}$ & & Yes \\
\hline $\begin{array}{l}\text { Manufacturing Data Analysis in Internet of } \\
\text { Things/Internet of Data (IoT/IoD) Scenario }\end{array}$ & & $\mathrm{X}$ & $\mathrm{X}$ & & $\mathrm{X}$ & & Yes \\
\hline $\begin{array}{l}\text { An artificial neural network approach for wafer dicing } \\
\text { saw quality prediction }\end{array}$ & $\mathrm{X}$ & $\mathrm{X}$ & $\mathrm{X}$ & & $\mathrm{X}$ & & Yes \\
\hline $\begin{array}{l}\text { Design framework for model-based self-optimizing } \\
\text { manufacturing systems }\end{array}$ & $\mathrm{X}$ & $\mathrm{X}$ & $\mathrm{X}$ & & $\mathrm{X}$ & & Yes \\
\hline $\begin{array}{l}\text { Cloud-based smart manufacturing for personalized candy } \\
\text { packing application }\end{array}$ & & $\mathrm{X}$ & & $\mathrm{X}$ & & $\mathrm{X}$ & No \\
\hline $\begin{array}{l}\text { Knowledge reasoning with semantic data for real-time } \\
\text { data processing in smart factory }\end{array}$ & $\mathrm{X}$ & $\mathrm{X}$ & $\mathrm{X}$ & & $\mathrm{X}$ & & Yes \\
\hline $\begin{array}{l}\text { Smart Innovation Engineering: Toward Intelligent } \\
\text { Industries of the Future }\end{array}$ & $\mathrm{X}$ & $\mathrm{X}$ & $\mathrm{X}$ & & $\mathrm{X}$ & & Yes \\
\hline $\begin{array}{l}\text { Quality managers and their future technological } \\
\text { expectations related to Industry } 4.0\end{array}$ & & & & & & $\mathrm{X}$ & No \\
\hline Toward New-Generation Intelligent Manufacturing & & & & & & $\mathrm{X}$ & No \\
\hline $\begin{array}{l}\text { A critical investigation of Industry } 4.0 \text { in manufacturing: } \\
\text { theoretical operationalization framework }\end{array}$ & & & & $\mathrm{X}$ & & $\mathrm{X}$ & No \\
\hline $\begin{array}{l}\text { Development of a Cyber-Physical framework for } \\
\text { monitoring and teleoperation of a CNC lathe based on } \\
\text { MTconnect and OPC protocols. }\end{array}$ & $X$ & $X$ & $X$ & & $X$ & & Yes \\
\hline
\end{tabular}

After reading, 9 articles were selected, thus finalizing the selection of articles. These were considered as reference articles. Through reading, it is possible to analyse the area of operation that each article is located, being able to understand if there is a specific area in which the most use of fault forecasting tools in manufacturing is used.

Through selection with articles, analysing how each author solved the problem presented. It is possible to highlight the use of ontological rules to sequence operations, previously manual, in a candy factory, preventing failures in the process, sequencing errors, improving the quality of the product.

The work of [9], brought concepts that contributed mainly to data mining for application in virtual reality techniques, however for this work, we used the concept of contained IoT.

The article by [10], portrays problems found in a manufacturing industry whose production processes are similar to the case study of this work, bringing manufacturing processes for machining and assembly. The purpose of this article is to improve connectivity and data collection. The article entries are similar to the scenario reported in this work, illustrating limitations, applications, and needs. 
These illustrations provided clarity for the scenario found in this work, offering input of ideas regarding the collection and treatment of data, and consequently its application. In this article, a tool for data collection called MTConnect was applied, which after this presentation, was considered to be used in this work and also allowed, from it, the exploration of similar technologies, promoting the knowledge of new techniques and algorithms.

The same reasoning was found through the article [11], which also contributed with another example of application for data collection, as well as its architecture/structure, to achieve an application for monitoring and remote operation of $\mathrm{CNC}$ machines, thus contributing to the interoperability of the manufacturing line, through this application.

The work of [12], also brought contributions regarding the impact of quality-ofservice parameters in the delay of communication from the production line to the cloud. This fact raised the need for evaluation for the case study of this work, since it had not been identified yet, and maybe a technological impediment to the collection, transmission, and communication of data between operations.

The article by [13], contributed to the application as to the need for decision-making processes using the knowledge and experiences of previous formal decision events, supporting the manufacturing as to decision making. This fact, which we found in the application of this work, as it was a noted element that for each measurement forecast to be performed, the method should be based on histories, comparing the current piece with the previous ones, contained in its training.

Another work with a similar contribution is that of [14], as it aims to intelligently and autonomously control the main characteristics of product and process quality. This fact was identified as a necessity in the case study of this work.

In the work of [15], brought the contribution of the concept involved in cloud processing, intelligent systems applied to improve interoperability in industrial manufacturing processes, mainly focused on fault detection and problem-solving based on data analysis. The fundamental concept brought by this work was the application of ontologies for the solution of the problem addressed.

The articles by [16][17][18], brought the key contribution to complement the construction of the Intelligent Fault Prediction and Identification System in Flexible Manufacturing, as these articles presented the application of neural networks and AI techniques (machine learning) to solve the problems presented, having as requirements: manage, analyse and process data, information and knowledge, using AI techniques, focusing on a system that supports decision making by reusing experience (history). The impact to be perceived is also in reducing waste, loss of products, efficiency of the process, thus contributing to the quality of the product.

It was also evident that most articles brought the problem of horizontal and vertical integration of information, involving problems of semantic interoperability of processes (between machines), which are related to product quality. The technology used in this problematization was the connection through ML techniques and neural networks, using Python programming, connection between machines using software and hardware (MTConnect, SIE, OPC), which brought satisfaction regarding the results obtained after its application [11].

Another conclusion by reading the articles is that even being impacted by the same cause of the problem, the application of the solution is never the same, as they are different expectations, different process limitations between companies, different database architecture, changing the approach and even the type of technique used between companies. 


\section{Concept of an Intelligent Product Quality Failure Prediction System}

In this way, these articles became the basis for the creation and development of a methodology that will act, through an Intelligent Product Quality Failure Prediction system (IPQFP), in predicting the results of products in flexible manufacture, and can be applied in any productive segment. Still, it can be adapted according to the transdisciplinary need for adequacy.

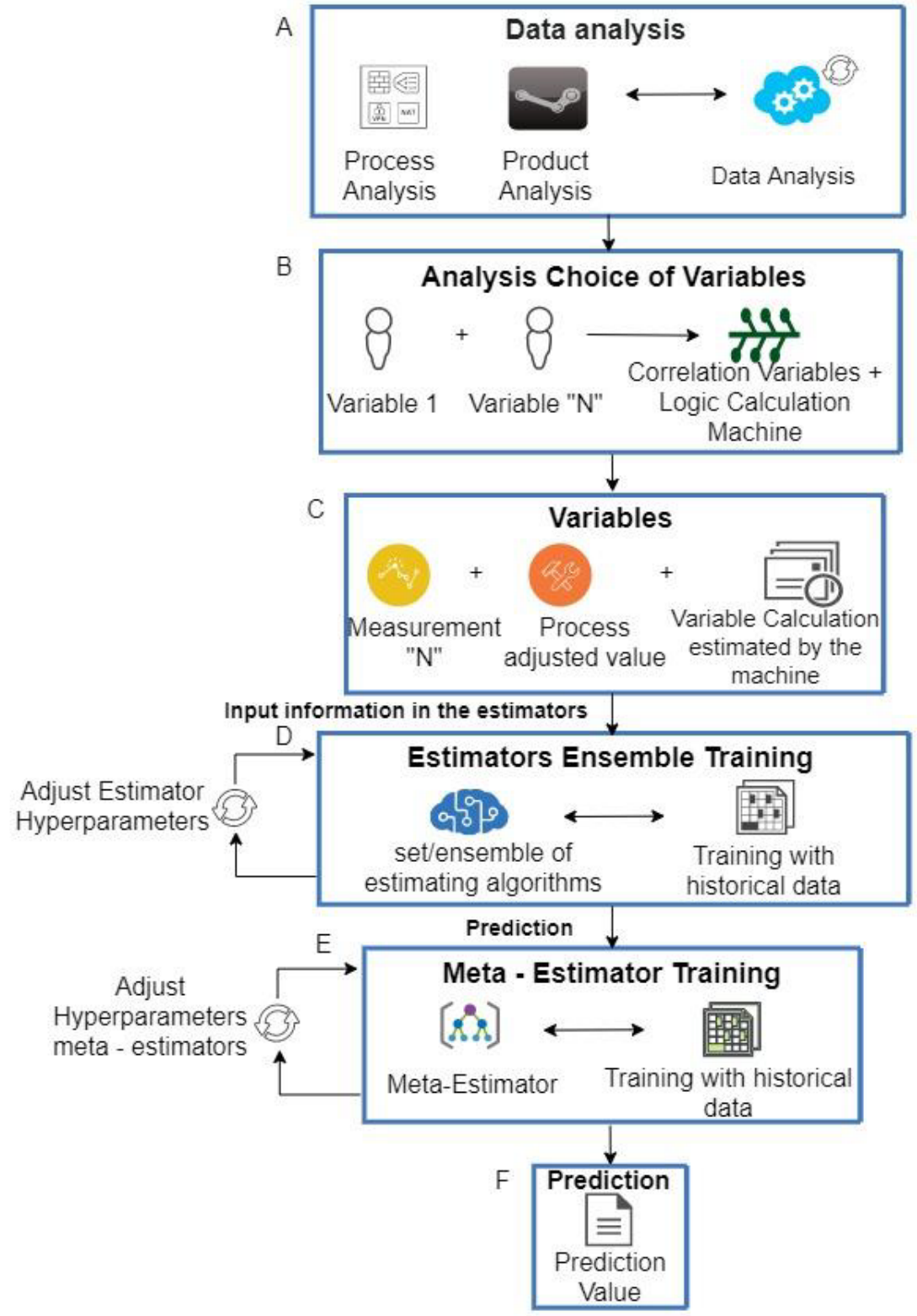

Figure 1. Structure of the IPQFP System 
This system is called IPQFP (Figure 1), it consists of a logical sequence of analyses, data collections, interpretations, creation of variables, data processing, application of artificial intelligence techniques, to produce an information forecast. This process shows transdisciplinarity since it encompasses several areas of knowledge involving the engineering perimeter.

Figure 1 shows the entire structure of the system, which consists of:

- Data analysis (Detail “A”): It is responsible for analyzing process and product data (Figure 2). The objective is to understand in detail its operation, its deviations, impacts on the product, standard deviation, oscillations, characteristics, influences of temperature and humidity, machine behavior, operator influence, statistical analysis, running performance throughout the day, under stops programs, under long periods of production stoppages and mainly to understand if there is a difference or impact between different types of products and product generations.

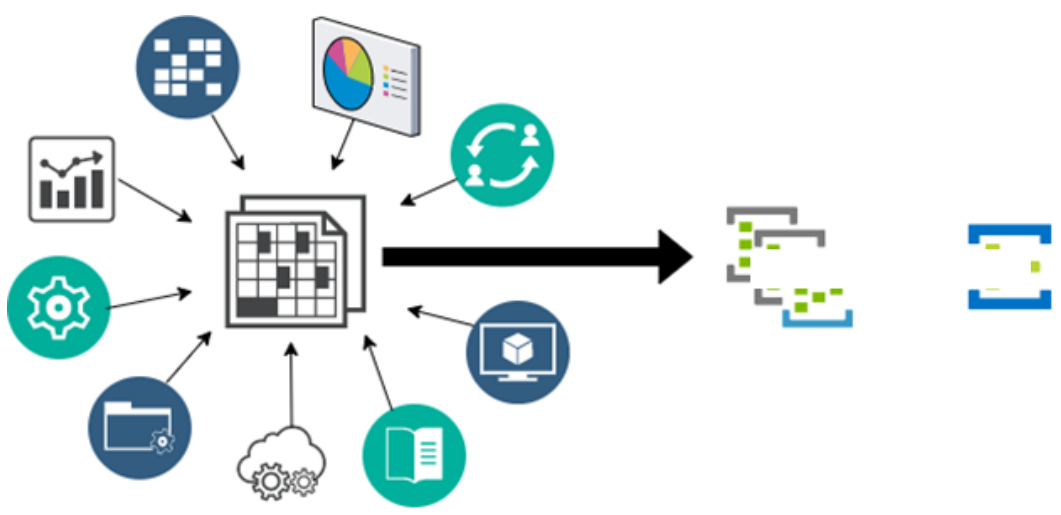

Figure 2. Data Analysis.

- Analysis and choice of variables (Detail "B"): It is dedicated to identifying all the potentials of variables, originated from the analysis of process, data, and product, which may be used for the training and validation of the algorithm models later. In the step of analyzing and choosing the variables, the variables already identified in the previous step are correlated with each other, through a correlation matrix and after identifying the most relevant ones, through an $\mathrm{ABC}$ curve analysis (Figure 3), the correlation with the logic is made of the processing unit.

Table 2. Correlation Matrix.

\begin{tabular}{|c|c|c|c|c|c|c|c|}
\hline & Operation & Op. 10 & Op. 11 & Op.12 & Op. 13 & Op. 14 & Op. 15 \\
\hline Operation & 1 & & & & & & \\
\hline Op. 10 & 0.06342 & 1 & & & & & \\
\hline Op. 11 & 0.12375 & 0.53468 & 1 & & & & \\
\hline Op. 12 & 0.41001 & 0.35711 & 0.17992 & 1 & & & \\
\hline Op. 13 & 0.25781 & -0.56731 & 0.65823 & 0.67537 & 1 & & \\
\hline Op. 14 & 0.35812 & -0.08753 & 0.54719 & -0.45923 & 0.46723 & 1 & \\
\hline Op. 15 & 0.08239 & -0.12282 & -0.75231 & 0.56261 & 0.35913 & 0.8733 & 1 \\
\hline
\end{tabular}




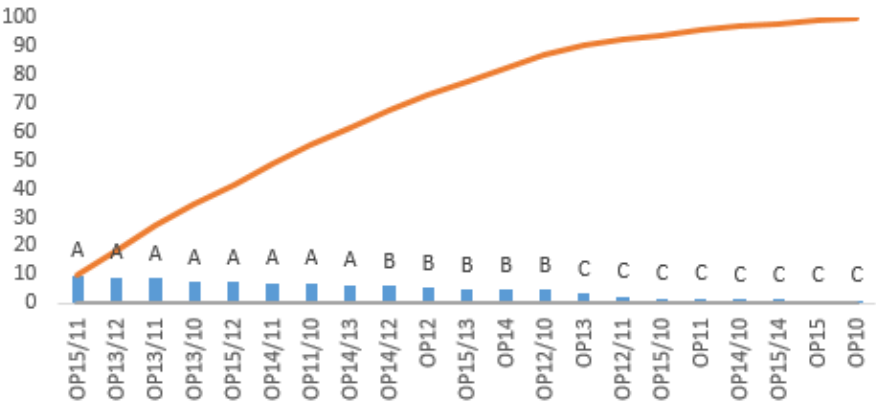

Figure 3. ABC Curve

- Variables (Detail "C"): It is the stage where the variables used by the machine logic are identified, forming a data entry, and processed by the line processing unit, obtaining an output variable, thus generating a data entry, called "Input information in estimators", for the next step.

- Estimator Ensemble Training (Detail “D”): it has a great role because it will receive inputs from the previous level, which will be processed in a set of algorithms and machine learning techniques. This processing will be the entrance to the training stage, which will add the variables identified as potential, to contribute to the training of the set of models (Figure 4).

Final Variables

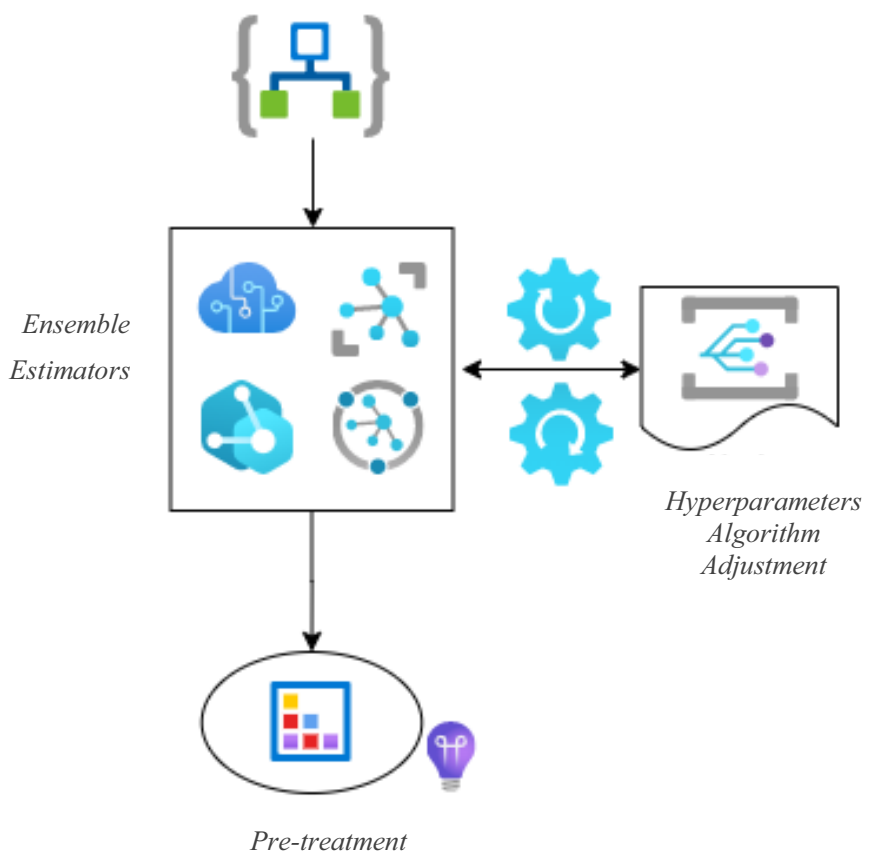

Figure 4. Estimator Ensemble Training 
- Meta-Estimator Training (Detail "E"): is responsible for processing the result in a model to complement, and ensure a better prediction of the result, bringing greater precision and reliability. The same occurs in a similar way to the previous step.

- Prediction (Detail "F"): This is the result of the prediction value.

\section{Result of the IPQFP application}

To measure the result, 2 scenarios were compared: production using AI versus production without using AI, in this same Product 1 . The same batch size was taken into account, as for the process, there were also no changes, maintenance that may impact the test result, as shown in Table 2 .

Table 2. Result of the application in a real case.

\begin{tabular}{|l|l|l|l|l|} 
Product & Quantity & $\begin{array}{l}\text { \% Error } \\
\text { reduction }\end{array}$ & $\begin{array}{l}\text { \% reduction mean } \\
\text { absolute error }\end{array}$ & $\begin{array}{l}\text { \% } \\
\text { deviation reduction }\end{array}$ \\
\hline Product 1 & 258 & $6,03 \%$ & $48,95 \%$ & $44,54 \%$ \\
\hline
\end{tabular}

According to the results presented, Product 1, in a batch of 258 units (parts), AI was shown to reduce $6.03 \%$ of errors, with about $\mathrm{R} \$ 5,000.00$ per year of savings in this product according to the volume produced, when compared to production not using AI. This represents that the AI proved to be more assertive than the standard process in question.

The mean absolute error, that is, it measures the difference between the exact value that you want to reach and its approximate value (expected), obtained a positive result, presenting an improvement of $48.95 \%$.

When the standard deviation is observed, that is, the dispersion among the batch of manufactured parts, it also presented a positive result, having an improvement of $44.54 \%$, which means that the process became more stable using the AI. This phenomenon is very important especially in types of products that have more precise characteristic tolerances, which makes the window between tolerance limits smaller.

\section{Conclusion}

Problems involving themes that address issues related to Industry 4.0 are still unknown for both the scientific and technical circles. Industry 4.0 is innovative, and as much as it is a technological evolution, its concepts are new, which challenges industries to adapt physically and socially to these addenda. Thus, when it is individualized by communication problems between machines, in particular, it can be seen that it is a characteristic problem of Industry 4.0, but it comes from several causes, among them the divergence between machine technologies, generating communication divergence between them and for problems originating from vertical and/or horizontal integration, in addition to human technological mastery and their social resistance.

Transdisciplinarity is present in this work addressing themes and disciplines that correlate to achieve a greater objective: IPQFP system, aiming as a final result to forecast results, measurements, increasing product quality, product and process reliability, in addition to increasing customer reliability and loyalty to the brand. 


\section{References}

[1] M. Ghobakhloo, The future of manufacturing industry: a strategic roadmap toward Industry 4.0. Journal of Manufacturing Technology Management, 2018, Vol. 29, No. 6, pp. 910-936.

[2] M. Zdravković, H. Panetto, The challenges of model-based systems engineer-ing for the next generation enterprise information systems. Information Systems and e-Business Management, 2017, Vol. 15, No. 2 , pp. $225-227$.

[3] B.S. Adamczyk, A.L. Szejka, O. Canciglieri Junior, Knowledge-based expert system to support the semantic interoperability in smart manufacturing. Computers in Industry, 2020, V. 115, 103161.

[4] A.L. Szejka, A. Aubry, H. Panetto, O. Canciglieri Junior, E.R. Loures, Towards a conceptual framework for requirements interoperability in complex systems engineering. Lecture Notes in Computer Science (including subseries Lecture Notes in Artificial Intelligence and Lecture Notes in Bioinformatics), 2014, Vol. 8842, pp. 229-240,.

[5] A.L. Szejka, O. Canciglieri Junior, E.R. Loures, H. Panetto, A. Aubry Requirements interoperability method to support integrated product development. In: Proceedings - CIE 45: 2015 International Conference on Computers and Industrial Engineering, Metz, 2015, pp. 1-10.

[6] F. Ma, Y. Chen, Y. Zhao, Research on the organization of user needs information in the big data environment. Electronic Library, 2017, Vol. 35, No. 1, pp. 36-49.

[7] S.K. Rao, R. Prasad, Impact of 5G Technologies on Industry 4.0. Wireless Personal Communications, 2018, Vol. 100, No. 1, pp. 145-159.

[8] A. Pirayesh Neghab, A. Etienne, M. Kleiner, L. Roucoules, Performance evaluation of collaboration in the design process: Using interoperability measurement. Computers in Industry, 2015, Vol. 72, pp. 14 26.

[9] J. J. Roldán, E. Crespo, A. Martín-Barrio, E. Peña-Tapia, A. Barrientos, A training system for Industry 4.0 operators in complex assem-blies based on virtual reality and process mining. Robotics and Computer-Integrated Manufacturing, 2019, Vol. 59, pp. 305-316,

[10] M. Colledani, T. Tolio, A. Fischer et al. Design and management of manufacturing systems for production quality. CIRP Annals - Manufacturing Technology, Vol. 63, n. 2, p. 773-796, 2014.

[11] A.J. Álvares, L.E.S Oliveira, J.C.E. Ferreira, Development of a Cyber-Physical framework for monitoring and teleoperation of a CNC lathe based on MTConnect and OPC protocols. International Journal of Computer Integrated Manufacturing, 2018, Vol. 31, No. 11, pp. 1049-1066.

[12] P. Ferrari, A. Flammini, S. Rinaldi et al. Impact of quality of service on cloud based industrial IoT applications with OPC UA. Electronics (Switzerland), 2018, Vol. 7, No. 7, pp. 1-14,

[13] M.M. Waris, C. Sanin, Szczerbicki, E. Smart Innovation Engineering: Toward Intelligent Industries of the Future. Cybernetics and Systems, 2018, Vol. 49, No. 5-6, pp. 339-354.

[14] U. Thombansen, G. Buchholz, D. Frank, et al. Design framework for model-based self-optimizing manufacturing systems. International Journal of Advanced Manufacturing Technology, 2018, Vol. 97, No. $1-4$, pp. 519-528.

[15] S. Wang, J. Wan, D. Li, C. Liu, Knowledge reasoning with semantic data for real-time data processing in smart factory. Sensors (Switzerland), 2018, Vol. 18, No. 2, pp. 1-10.

[16] S.I. Shafiq, E. Szczerbicki, C. Sanin, Manufacturing Data Analysis in Internet of Things/Internet of Data (IoT/IoD) Scenario. Cybernetics and Systems, 2018, Vol. 49, No. 5-6, pp. 280-295.

[17] T.J. Su, Y.F. Chen, J.C. Cheng, C.L. Chiu, An artificial neural network approach for wafer dicing saw quality prediction. Microelectronics Reliability, 2018, Vol. 91, No. 9, pp. 257-261.

[18] S. Wang, J. Wan, M. Imran, D. Li, C. Zhang, Cloud-based smart manufac-turing for personalized candy packing application. Journal of Supercomputing, 2018, Vol. 74, No. 9, pp. 4339-4357. 